\title{
A system of screening for the presence of a number of common drugs
}

\author{
MERLE DUNLOP AND D. H. CURNOW \\ From the Department of Biochemistry, Royal Perth Hospital, Perth, Western Australia
}

SYNOPSIS A method is described to provide a rapid screening technique for the presence of barbiturates, glutethimide, carbromal, meprobamate, salicylate, phenothiazine derivatives, bromide, carbon monoxide, and alcohol.

Phenothiazines are detected by a spot urine test. The first four drugs are identified, within 60 minutes of blood collection, on thin-layer chromatoplates of microscope slide dimensions. The estimations of bromide, salicylate, carbon monoxide, and of alcohol levels are started in that period so the overall time for the screening is less than two hours, and the amount of blood required is only $10 \mathrm{ml}$.

With the increasing incidence of drug addiction and drug poisoning it has become essential for clinical biochemical laboratories to provide a service for the rapid detection of a wide selection of exogenous toxic compounds. Our investigations have been aimed at producing a simple routine, yielding in the shortest possible time information of extreme importance in the diagnosis and treatment of the comatose patient. A somewhat similar approach to the problem is taken by Curry (1966) and some of his methods are useful supplements to those reported here.

After consultation with physicians and the pharmacy department of Royal Perth Hospital it was decided to screen patients for the presence of barbiturates, salicylates, glutethimide, carbromal, meprobamate, bromide, phenothiazine derivatives, carbon monoxide, and alcohol.

The requirements of any technique to be developed as a suitable routine service are rapidity, sensitivity, and robustness: rapidity for the urgent cases of overdose which present frequently at a casualty department; sensitivity for the cases of drug addiction forwarded from the psychiatric clinic; and robustness for the non-specialist to handle on emergency duty. To fulfil these requirements the rapid thin-layer chromatographic technique is used with the modification of Hofmann (1962), i.e., the preparation of microscope slides for the chromatography. Before chromatography the drugs in the blood are separated into two groups: the neutral group, including glutethimide, carbromal, mepro-

Received for publication 24 October 1966. bamate; and the acidic group containing barbiturates. Blood carbon monoxide and alcohol levels are both measured by diffusion methods and plasma bromide by a gold chloride method. The basic phenothiazine derivatives are detected in the urine.

\section{MATERIALS}

PREPARATION OF CHROMATOPLATES The microscope slides are spread with a slurry of silica gel G (Merck, for T.L.C.) to a thickness of $12 \times 10^{-3}$ inch. (A small template was constructed by the Instrument Department of the hospital for the preparation of the plates and a feeler gauge was used to determine the silica gel thickness.)

The plates are allowed to dry on the template for five minutes, then carefully separated. After a further 15 minutes at room temperature the plates are dried in an oven with a draught at $45^{\circ} \mathrm{C}$. for 30 minutes. Finally they are activated at 100 to $105^{\circ} \mathrm{C}$. for 30 minutes.

By warming at $45^{\circ} \mathrm{C}$. preparatory to activation the cracking, due to differing amounts of shrinkage of the silica gel and the binding agent (Dohmann, 1965), is greatly decreased and does not present any problems in the running of the chromatograms.

The plates are stored in a desiccator and retain their activity for several weeks.

REAGENTS The following are the general reagents: $\mathrm{NaCl} 0.9 \%, \mathrm{HCl} 0.5 \mathrm{~N}, \mathrm{NaOH} 0.45 \mathrm{~N}$, chloroform (Baker analysed), and methanol A.R. (Merck) although one bottle of Merck methanol had enough amine contamination to interfere in the colour development of chromatoplates.

Chromatography solvent Methanol : chloroform $(9: 91 \mathrm{v} / \mathrm{v})$ (stable five days). 
Hypochlorite solution $\mathrm{NaOC1}$ (containing 10-13\% available chlorine), $20 \mathrm{ml}$, is diluted to $100 \mathrm{ml}$. with $\mathrm{H}_{2} \mathrm{O}$.

Potassium iodide-starch reagent Starch $(2$ g. $)$ is softened with a little water and added to $90 \mathrm{ml}$. boiling water containing 1 g.KI. The solution is boiled for one minute with constant stirring, allowed to cool and made up to $100 \mathrm{ml}$. with $\mathrm{H}_{2} \mathrm{O}$. It is stored at $4^{\circ} \mathrm{C}$.

Potassium chloride-boric acid buffer (0.6M) Boric acid $9.3 \mathrm{~g}$., and $11.2 \mathrm{~g} . \mathrm{KCl}$ are dissolved in water and the volume made up to $250 \mathrm{ml}$. (It may be several hours before the boric acid goes completely into solution even with frequent shaking.)

Standards Two are made up: mixed standard A, glutethimide (100 mg.), meprobamate (200 mg.), and carbromal (400 mg.) in $100 \mathrm{ml}$. acetone; mixed standard B, pentobarbitone $(100 \mathrm{mg}$.) and phenobarbitone (100 mg.) in $100 \mathrm{ml}$. chloroform.

\section{METHODS}

PREPARATION OF EXTRACTS (NEUTRAL AND ACIDIC FRACTIONS) The extraction procedure is outlined in the flow sheet (scheme 1). Plasma $(2 \mathrm{ml}$.) is adjusted with $0.5 \mathrm{~N} \mathrm{HCl}$ to $p \mathrm{H} 6$ and extracted with $15 \mathrm{ml}$. chloroform in a $50 \mathrm{ml}$. separating funnel. The chloroform layer is filtered (Whatman paper no. 1) into a second separating funnel. The extraction is repeated with a further $15 \mathrm{ml}$. chloroform. The combined chloroform extracts are then shaken with $10 \mathrm{ml}$. $0.45 \mathrm{~N} \mathrm{NaOH}$ for 2 to 3 minutes. The chloroform layer is filtered into a $50 \mathrm{ml}$. Quickfit tube and gently evaporated to dryness under vacuum at a temperature below $70^{\circ} \mathrm{C}$. to avoid decomposition (Goldbaum, Williams, and Koppanyi, 1960). This fraction contains the neutral drugs glutethimide, carbromal, and meprobamate, and is called extract 1.

Of the aqueous alkaline solution in the separating funnel, $5 \mathrm{ml}$. is pipetted into a glass tube and kept for measurement of the barbiturate concentration if required.

The remaining $5 \mathrm{ml}$. of the aqueous alkaline layer is acidified and extracted with $25 \mathrm{ml}$. chloroform. The chloroform layer is filtered into a Quickfit tube and gently evaporated to dryness. This fraction contains the barbiturates and is called extract 2 .

CHROMATOGRAPHY At a position $15 \mathrm{~mm}$. from the end and $8 \mathrm{~mm}$. from one side of a microchromatoplate $10 \mu \mathrm{l}$. of mixed standard solution A (meprobamate, carbromal, glutethimide) is applied, using a disposable pipette (microcap). Extract 1, taken up in 20-30 $\mu \mathrm{l}$. acetone, is spotted on level with the standard and $8 \mathrm{~mm}$. from the other side of the plate. On a second microchromatoplate $10 \mu \mathrm{l}$. of mixed standard B (pentobarbitone, phenobarbitone) is applied. Extract 2, taken up in 20-30 $\mu$ l. chloroform, is spotted on level with the standard.

A screw-top jar serves as the chromatography tank and a Conway unit base as the holder for the plates. The two plates are placed in the outside well of the unit in the tank. The solvent $(10 \mathrm{ml}$.) is pipetted into the unit, then the lid is quickly screwed on the tank. After 16 minutes the plates are removed and dried at room temperature.
IDENTIFICATION A non-specific colour reaction developed by Rydon and Smith (1952) is used for the identification of glutethimide, carbromal, meprobamate, and barbiturate derivatives.

The two plates, supported almost vertically, are finely sprayed with sodium hypochlorite solution from a modified glass nebulizer. (The outer glass wall of the nebulizer is cut off at the level of the spray unit.) Approximately 30 seconds later the chlorine has evaporated from the inert silica gel. The plates are then sprayed with the potassium iodide-starch solution, using a pressure pack. An intense blue colour develops due to the liberation of iodine by the $\mathrm{N}$-chloro compounds formed in the chlorination step. The drugs are identified by blue spots on a white background, the colour fading to brown in a few hours.

Timing the second spraying so that the background is clear but the unstable $\mathrm{N}$-chloro compounds have not decomposed is the critical step in the detection of these drugs. The plates can be tested for excess chlorine by spotting 1-2 $\mu \mathrm{l}$. of the KI-starch solution on trial portions of the plate (e.g., the extreme lower section) at intervals of two to three seconds. When the trial spot is very pale blue or colourless the plates are then sprayed with the KI-starch solution. The microchromatoplates are suited to this method of colour development because even spraying is ensured over the small area.

MEASUREMENT OF THE BARBITURATE CONCENTRATION If barbiturate is detected by the chromatographic technique the level is measured by the method of Broughton (1956) in the $5 \mathrm{ml}$. aliquot put aside during the extraction procedure.

A standard, of $0.2 \mathrm{ml}$. of $0.1 \%$ solution of diethyl barbituric acid and $2 \mathrm{ml}$. saline, is extracted in the same way as the patient's plasma. Having already identified barbiturate the spectrum from 225 to $265 \mathrm{~m} \mu$ is not read but only the difference in optical density of the $p \mathrm{H} 13.4$ and $p \mathrm{H} 10.0$ solutions at $260 \mathrm{~m} \mu$.

It is known that salicylate interferes with the measurement of barbiturate by this method and, although it is common elsewhere for these two drugs to be present simultaneously, only one such case has been detected at this hospital in the last six months.

SALICYLATE The plasma salicylate level is measured by the method of Trinder (1954).

BROMIDE The plasma bromide level is determined by the method of Barbour, Pilkington, and Sargant (1936) with modifications (Dunlop, 1966). The volumes are: $1 \mathrm{ml}$. plasma, $6 \mathrm{ml} .0 .5 \%$ sodium chloride, and $1 \mathrm{ml} .30 \%$ trichloracetic acid. After 10 minutes the mixture is filtered through Whatman no. 42 paper and $0.5 \mathrm{ml} .0 .5 \%$ gold chloride solution is added to $4 \mathrm{ml}$. filtrate. The test solutions and appropriate standards are read in a colorimeter at $470 \mathrm{~m} \mu$.

PHENOTHIAZINES IN URINE Phenothiazine derivatives are detected by a spot test developed by Forrest, Forrest, and Mason (1961) using a ferric chloride, perchloric acid, nitric acid (F.P.N.) reagent which reacts with the 
partially oxidized highly reactive intermediary metabolites of phenothiazines found in urine.

ALCOHOL Alcohol is measured by the method of Williams, Linn, and Zak (1958) with one modification, that of temperature. For convenience the incubation temperature of $56^{\circ} \mathrm{C}$. was changed to $37^{\circ} \mathrm{C}$. and it was found that the diffusion equilibrium was still obtained in 60 minutes.

CARbon monoxide Carbon monoxide is detected and measured by the method described by Conway (1962), based on the diffusion of carbon monoxide into palladium chloride with the formation of a palladium mirror and hydrochloric acid. This method is also modified. The diffusion temperature is increased to $37^{\circ} \mathrm{C}$. Diffusion is complete in 60 minutes and the level of carbon monoxide is measured by titration of the acid formed.

In an emergency two units are set up initially, one with diluted blood to diffuse for 60 minutes and the other with undiluted blood to diffuse for 15 minutes at $37^{\circ} \mathrm{C}$. After the 15 minutes this second unit is examined for the formation of a palladium mirror indicating the presence of carbon monoxide in the blood.

RESULTS

Figure 1 shows the separation of the neutral drugs glutethimide ( $\left.R_{f} 0.96\right)$, carbromal $\left(R_{f} 0.87\right)$, and meprobamate $\left(\mathbf{R}_{\mathbf{f}} \mathbf{0 . 2 7}\right)$ located by $\mathrm{NaOC1}-\mathrm{KI}-$ starch reaction.

Seven barbiturates (pheno-, pento-, amylo-, hexo-, quinal-, butobarbitone, and barbitone) were studied, representing the most commonly dispensed barbiturates at this hospital.

The thin-layer chromatography of these seven barbiturates showed two groups: (1) phenobarbitone and barbitone, the slow acting barbiturates, running slowly with an $R_{f}$ of 0.44 on these small plates; and (2) the intermediate or fast acting barbiturates, running faster than the first group, with an $R_{\mathfrak{f}}$ of 0.54.

Figure 1 illustrates the separation of these two groups, located by the $\mathrm{NaOC1}-\mathrm{KI}$-starch reaction.

The sensitivity obtained is $1 \mu \mathrm{g}$. for barbiturates and glutethimide, $5 \mu \mathrm{g}$. for meprobamate, and $10 \mu \mathrm{g}$. for carbromal.

A recovery of $90 \%$ for diethyl barbituric acid at the level equivalent to $10 \mathrm{mg} . / 100 \mathrm{ml}$. plasma has been obtained by this extraction procedure. In patients, levels up to $15 \mathrm{mg} . / 100 \mathrm{ml}$. plasma have been measured with negligible loss into the neutral extract.

Similarly, glutethimide levels of approximately $15 \mathrm{mg} . / 100 \mathrm{ml}$. plasma have been measured, the acidic extract remaining clear. (The glutethimide

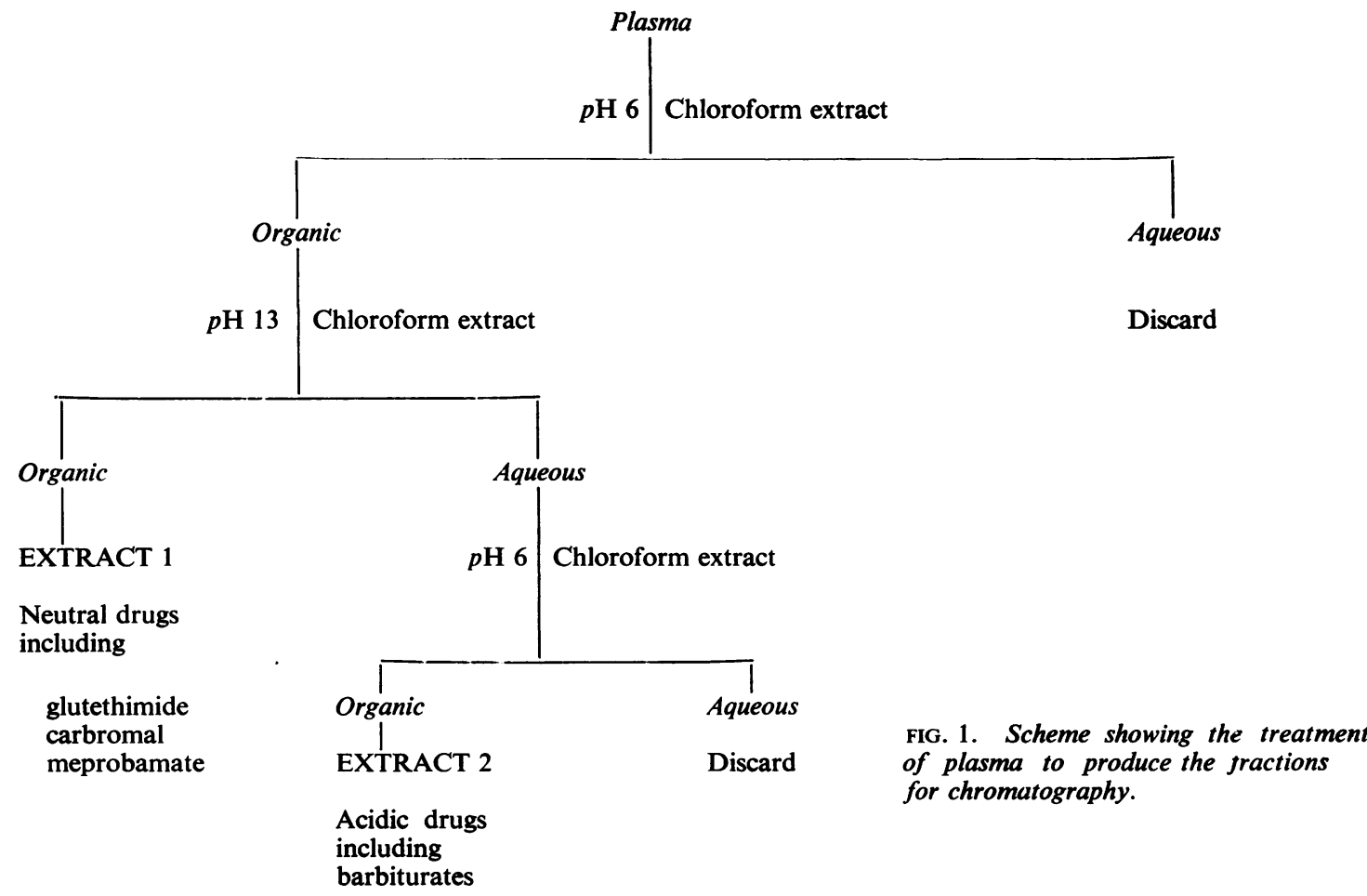




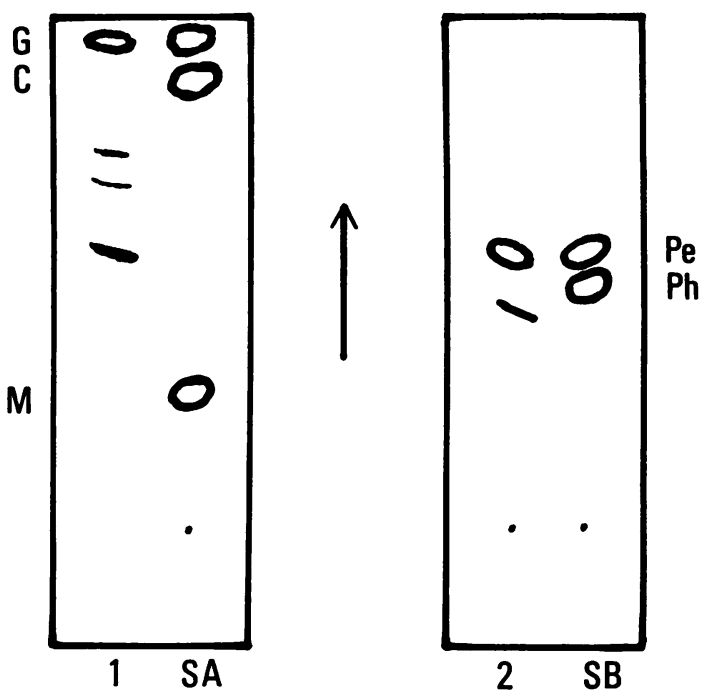

FIG. 2. Chromatogram of neutral and acidic extracts. $G$ glutethimide, $C$ carbromal, $M$ meprobamate, Pe pentobarbitone, $P h$ phenobarbitone.

1 , extract 1 containing glutethimide.

2 , extract 2 containing an intermediate or fast acting barbiturate.

$S A$ mixed standard $A, S B$ mixed standard $B$.

Thin layer, silica gel.

Solvent, methanol : chloroform (9:91).

Time, 16 min.

level was obtained by comparing the size of spots. (The aliquot of extract applied to the plate was altered until the spot corresponded to the standard.)

The spot test for the detection of urinary phenothiazine derivatives was found to give a false positive in one instance. On addition of acid only to the urine a strong purple colour formed immediately, suggesting the presence of an indicator type substance in the urine. In this case chromatography of a urine extract (Cochin and Daly, 1962) gave negative results with iodoplatinate reagent. All positive urinary F.P.N. (ferric chloride perchloric nitric acid) tests are now checked by testing the urine with acid. No false negative results were obtained in 20 cases when both the spot test and chromatography were carried out.

The carbon monoxide method is extremely sensitive. When undiluted blood is used in the unit incubated for only 15 minutes the presence of the gas can be detected at a level of $1 \%$ of maximum saturation, the concentration being estimated on the unit incubated for 60 minutes.

The alcohol is measured after 60 minutes incubation by a colour reaction involving brucine. Some time is lost at this stage of the procedure but if the case is urgent the presence of alcohol is visible to the eye by a change in colour of the dichromate solution in the centre well. This diffusion method is not specific for ethanol, but also detects methanol and acetone.

The normal levels for plasma bromide and salicylate are quoted at $<4 \mathrm{mg} . / 100 \mathrm{ml}$. and $<2 \mathrm{mg}$. $/ 100 \mathrm{ml}$. respectively and are a measure of the errors inherent in the methods at the very low levels.

\section{DISCUSSION}

Table I shows the total number of cases investigated for the presence of drugs in 1962 and 1965 indicating the increasing incidence of poisonings and addictions.

TABLE I

SUMMARY OF RESULTS

\begin{tabular}{lcr}
\hline & Year & \\
& 1962 & 1965 \\
No. of cases investigated & 260 & 400 \\
$\begin{array}{l}\text { Drugs detected: } \\
\text { Barbiturate }\end{array}$ & 150 & \\
Bromide & 30 & 210 \\
Glutethimide & 3 & 69 \\
Phenothiazines & 6 & 4 \\
Salicylate & 3 & 9 \\
& & 6
\end{tabular}

It is essential to separate the drugs into the neutral and acidic groups before chromatography because of possible interference in identification due to metabolites. This is best illustrated in Figure 1 where the metabolites of glutethimide are shown diagrammatically. If the two extracts were run as one a falsely positive barbiturate identification could be made. The glutethimide metabolite pattern is detected on the plates in less than 24 hours after ingestion. Wallenius, Zaar, and Lausing (1963) noted interference by glutethimide in their colour reaction for the detection of barbiturates.

Carbromal, a brominated mono-ureide, is hydrolysed in vivo to produce 2-ethyl-butyryl urea and bromide. Shortly after ingestion the carbromal may be located on the plate, but a few hours later it is barely detectable and the bromide ion can then be measured colorimetrically.

There are many methods available for the detection of barbiturates, such as the ingenious spot tests by Wallenius et al. (1963), Curry (1963) and Baer (1965), paper chromatography with modifications by Podmore (1962) and Waddell (1965), and thin-layer chromatography by Schmidt (1962) and Lehmann and Karamustafaoglu (1962). These chromatographic techniques provide a more detailed analysis of the barbiturates present than the method described here. However, the separation of the barbiturate derivatives into only two groups, the 
slow acting or non-metabolized and the intermediate or fast acting (i.e. metabolized) is adequate for our clinical purposes. Lee and Ames (1965) base their decisions for haemodialysis on the group and level of barbiturate present and whether taken concurrently with phenothiazines.

Jackson (1963) describes a system of paper chromatography which covers a considerable number of drugs but the chromatography requires at least two hours. The reverse phase high temperature paper chromatography technique developed by Street (1962) provides a more rapid screen. However, thin-layer chromatography, apart from its rapidity, is extremely robust, giving good resolution of barbiturates over a range of 1 to $150 \mu \mathrm{g}$., making it applicable for cases both of addiction and overdose.

The simple method of using one reagent to detect all the neutral and acidic drugs has proved to be rapid, reliable, and sensitive. The plates are easier to read at the low levels frequently encountered than the method of alkalinization and viewing under ultra-violet light at $253 \mathrm{~m} \mu$. Podmore (1962) reports a sensitivity of 10 to $20 \mu \mathrm{g}$. for barbiturates by the latter method.

Sunshine (1963) and Cochin and Daly (1963) also use thin-layer chromatography for the detection of a wide array of compounds, but on the standard $20 \mathrm{~cm}$. plates, thereby increasing the time interval before identification.

The microchromatoplates provide a simple, rapid technique and it was found that, with the system described, the separation was not improved when the larger plates were used.

We wish to thank Mr. J. T. Wearne for his help in this study.

\section{REFERENCES}

Baer, D. M. (1965). Amer. J. clin. Path., 44, 114.

Barbour, R., Pilkington, F., and Sargant, W. (1936). Brit. med. J., 2, 957.

Broughton, P. M. G. (1956). Biochem. J., 63, 207.

Cochin, J., and Daly, J. W. (1962). Experientia (Basel), 18, 294.

- - (1963). J. Pharmacol. exp. Ther., 139, 154

Conway, E. J. (1962). Microdiffusion Analysis and Volumetric Error, 5th edition. Crosby, Lockwood, London.

Curry, A. S. (1963). Brit. med. J., 2, 1040.

- (1966). Ass. clin. Path. Broadsheets, n.s., 52.

Dohmann, K. (1965). Lab. Pract., 14, 808. Psychiat., 118, 300.

Goldbaum, L. R., Williams, M. A., and Koppanyi, T. (1960). Anal. Chem., 32, 81 .

Hofmann, A. F. (1962). Anal. Biochem., 3, 145.

Jackson, J. V. (1963). Proc. Ass. clin. Biochem. 2, 128.

Lee, H. A., and Ames, A. C. (1965). Brit. med. J., 1, 1217.

Lehmann, J., and Karamustafaoğlu, V. (1962). Scand. J. clin. Lab. Invest., 14, 554.

Podmore, D. A. (1962). Clin. chim. Acta, 7, 176.

Rydon, H. N., and Smith, P. W. G. (1952). Nature (Lond.), 169, 922. Schmidt, G. (1962). In Methods of Forensic Science, Vol. 1, edited by F. Lundquist, p. 373. Interscience Publishers, New York.

Smith, I. (1960). Chromatographic and Electrophoretic Techniques, 2nd ed., Vol. 1. Heinemann, London.

Street, H. V. (1962). J. forens. Sci., 7, 222.

Sunshine, I. (1963). Amer. J. clin. Path., 40, 576.

Trinder, P. (1954). Biochem. J., 57, 301.

Waddell, W. J. (1965). Clin. Chem., 11, 37.

Wallenius, G., Zaar, B., and Lausing, E. (1963). Scand. J. clin. Lab. Invest., 15, (Suppl. 69), 252.

Williams, L. A., Linn, R. A., and Zak, B. (1958). Clin. chim. Acta, 3, 169.

\section{Reports and Bulletins prepared by the Association of Clinical Biochemists}

The following reports and bulletins are published by the Association of Clinical Biochemists. They may be obtained from Mr. J. T. Ireland, Biochemistry Laboratory, Alder Hey Children's Hospital, Liverpool, 12. The prices include postage, but airmail will be charged extra.

\section{SCIENTIFIC REPORTS}

1 Colorimeters with Flow Through Cells. A Critical Assessment of 4 Instruments. 1965. P. M. G. BROUGHTON and C. RILEY. $13 \mathrm{~s} 6 \mathrm{~d}$.

2 Colorimeters: A critical assessment of 5 commercial instruments. 1966. P. M. G. BROUGHTON, C. RILEY, J. G. H. COOK, P. G. SANDERS and H. BRAUNSBERG. 15 s.

\section{TECHNICAL BULLETINS}

2 A Report on the Enzyme Questionnaire Circulated by the Scientific Committee. December 1964. A. H. GOWENLOCK. $1 \mathrm{~s}$.

3 Non-recording Spectrophotometers for the Visible and Ultraviolet Ranges. A comparative table of instruments available in Great Britain. May 1965. A. H.
GOWENLOCK, P. C. NICHOLAS, and J. H. WILKINSON. 1s. 6d.

4 Control Solutions for Clinical Biochemistry. June 1965. P. M. G. BROUGHTON and A. H. GOWENLOCK. N 1s. 6d.

5 Recording Spectrophotometers. A comparative list of low-priced instruments readily available in Britain. July 1965 . P. SEWELL. 2s. 6d.

6 A Guide to Automatic Pipettes. A list of more than 100 instruments compiled from manufacturers' literature. $\stackrel{?}{+}$ August 1965. P. M. G. BROUGHTON. 5s.

7 Variability Between Auto-Analyzer Modules. August 1965. B. E. NORTHAM. 1s. 6 d.

8 Flame Photometers. A comparative list of 15 instruments readily available in Britain. June 1966. C. RILEY. 4s. 